\title{
The Role of Serum Ascites Albumin Gradient in the Differential Diagnosis of Ascites.
}

\author{
Hysni Dede ${ }^{1 *}$, Rovena Roshi ${ }^{2}$, Rovena Bode ${ }^{3}$, Enver Roshi ${ }^{4}$, Jovan Basho ${ }^{4,5}$
}

Received: 07 December 2021 / Accepted: 29 December 2021 / Published online: 20 January 2022

This article is published with open access at https://journal.astes.org.al

(C) The author(s) 2022. \& Copyright (C) 2022, the Albanian Society for Trauma and Emergency Surgery

(c) The Albanian Journal of Trauma and Emergency Surgery is an Open Access Journal. All articles are distributed under the terms of the Creative Commons Attribution Non-Commercial License: http://creativecommons.org/licenses/by-nc/4.0/) which permits unrestricted non-commercial use, distribution, and reproduction in any medium provided the original work is properly cited.

\begin{abstract}
Introduction: Ascites is of Greek derivation ("askos") and refers to a bag or sack. The word is a noun and describes pathologic fluid accumulation within the peritoneal cavity. Orientation in finding or excluding portal hypertension through examination of ascitic fluid is the first step towards an accurate diagnosis.

Material and Methods: The aim of this study was to evaluate the role of SAAG (Serum Ascites Albumin Gradient) in the differential diagnosis between cirrhotic and malignant ascites. The SAAG is obtained by subtracting the value of serum albumin, the value of ascites albumin (from samples to be taken on the same day) and is a reflection of hepatic sinusoidal pressure.

Result: All ascitic fluids were analyzed on the laboratory parameters of ascitic albumin values and at the same time serological albumin through the blood was taken for analysis on the same day as the diagnostic paracentesis. The value of SAAG was calculated for each patient between their two groups: 64 patients with cirrhotic ascites and 8 patients with malignant ascites. Higher SAAG values were found in the group of patients with hepatic cirrhosis $(2.02 \pm 0.42)$ compared to the group of patients with malignant pathology $(0.68 \pm 0.19)$.

Conclusion: This prospective study showed statistically significant differences $(p<0.0001)$ between cirrhotic ascites and malignant ascites in terms of SAAG, emphasizing the important role of diagnostic paracentesis and in particular the SAAG in the differential diagnosis of ascitic fluid, in accordance with cut-off values $\geq 1.1 \mathrm{~g} / \mathrm{dl}$ referring to ascites from portal hypertension, which suggests a nonperitoneal cause of ascites.
\end{abstract}

Keywords: SAAG, ascites, diagnostic paracentesis, albumin gradient, cirrhotic ascites, malignant ascites

\section{Abbreviations}

Serum Ascites Albumin Gradient - SAAG; Ascites protein level - Asc prot; Hepatic Venous Pressure Gradient-HVPG; University Hospital Center - UHC; Computed Tomography - CT; Magnetic Resonance Imaging - MRI; Statistical Package for Social Sciences - SPSS; American Society for the Study of Liver Disease - AASLD; The European Association for the Study of Liver - EASL;

Original article, no submission or publication in advance or in parallel

* Corresponding author:

Hysni Dede MD

$\triangle$ ninidede2003@yahoo.com

1 Gastro-hepathologist in German Hospital International, Tirana, ALBANIA

2 Primary Health Care Physician, Tirana, ALBANIA

3 Surgery Service, University Hospital Center "Mother Teresa” Tirana, ALBANIA

4 University of Medicine of Tirana, ALBANIA

5 Gastro-hepatology Service University Hospital Center "Mother Teresa" Tirana, ALBANIA

\section{Introduction:}

Ascites is of Greek derivation ("askos") and refers to a bag or sack. The word is a noun and describes pathologic fluid accumulation within the peritoneal cavity.[1]

Fluid accumulation in the abdomen was recognized in ancient times. Celsius is credited with first describing in $\sim 20$ B.C. the technique of paracentesis for aspirating fluid from the peritoneal cavity, using a bronze tube with a flanged collar to drain fluid.

One of the famous patients to receive large volume paracenteses was Ludwig van Beethoven in 1827.[2]

The adjective ascitic is used in conjunction with the word fluid to describe the liquid per se. Therefore, "ascitic fluid" is preferred to "ascites fluid." [3] Healthy men have little or no intraperitoneal fluid, but women may normally have as much as $20 \mathrm{~mL}$, depending on the phase of their menstrual cycle [1].

In liver disease, ascites indicates a chronic or subacute disorder and does not occur in acute conditions (e.g., uncomplicated viral hepatitis, drug reactions, biliary 
obstruction). The most common cause is cirrhosis, especially from alcoholism. Other hepatic causes include chronic hepatitis, severe alcoholic hepatitis without cirrhosis, and hepatic vein obstruction (Budd-Chiari syndrome).

Portal vein thrombosis does not usually cause ascites unless hepatocellular damage is also present.

Non-hepatic causes of ascites include generalized fluid retention associated with systemic disease (e.g., heart failure, nephrotic syndrome, severe hypoalbuminemia, constrictive pericarditis) and intra-abdominal disorders (e.g., carcinomatosis, tuberculous peritonitis).

Hypothyroidism occasionally causes marked ascites, and pancreatitis rarely causes large amounts of fluid (pancreatic ascites). Patients with renal failure, especially those on hemodialysis, occasionally develop unexplained intra-abdominal fluid (nephrogenic ascites) [4]

In the Western world, cirrhosis is the main cause of ascites, accounting for more than $75 \%$ of the cases (Tab.1). Other, less common causes of ascites are peritoneal malignancy in $\sim 12 \%$, and cardiac failure in $5 \%$. Peritoneal tuberculosis accounts for only $2 \%$ of the cases in the Western World, but is still an important cause of ascites in many developing countries.

Approximately 5\% of patients will have more than one cause of ascites, such as cirrhosis and heart failure, cirrhosis and tuberculous peritonitis, or cirrhosis and malignancy [5].
Ascites total protein content at different cutoff values (2.5- $\mathrm{g} / \mathrm{d} \mathrm{L}$ ) has been traditionally used to divide ascitic fluid into "exudates" secondary to peritoneal processes (malignancy. tuberculosis) or "transudates" in case of ascites secondary to sinusoidal portal hypertension. It is increased in peritoneal processes because of leakage of high protein mesenteric lymph obstructed lymphatics and/or from an inflamed peritoneum. However, exudative ascites is also present in ascites secondary to heart failure. All causes of ascites and their known/expected SAAG and total protein levels are shown in Table 1. The diagnostic workup for the three main causes of ascites is outlined in Figure 1.[5]

The classification of ascites as 'exudative' and 'transudative' based on ascitic fluid total protein (AFTP) has been challenged in many clinical conditions like cardiac ascites, patients on prolonged diuretic therapy and malignant ascites because it had poor diagnostic efficacy. These drawbacks have led to the development of another approach to classify ascites, which is based on SerumAscites Albumin Gradient (SAAG) to differentiate ascitic fluid into two categories: SAAG $>$ or $=1.1 \mathrm{mg} / \mathrm{L}$ in ascites due to portal hypertension and $\mathrm{SAAG}<1.1 \mathrm{mg} / \mathrm{L}$ in ascites unrelated to portal hypertension. [6]

The SAAG is obtained by subtracting ascites albumin from serum albumin (from samples to be taken on the same day) and is a reflection of hepatic sinusoidal pressure $[7,8]$ The SAAG concept is based on Starling forces. When

Table 1. Distribution of ascitic fluid in according the ethiological factor

\begin{tabular}{|l|l|l|}
\hline \multicolumn{2}{|l|}{ SAAG } & Ascites protein \\
\hline The main etiological factors of ascites & High & Low \\
\hline Cirrhosis or alcoholic hepatitis & High & High \\
\hline Congestive heart failure & Low & High \\
\hline Malignant peritoneal pathologies & Low & High \\
\hline Peritoneal tuberculosis & High \\
\hline Other etiological factors (account for <2\% of all cases) & Low \\
\hline Massive hepatic metastasis & High & Low \\
\hline Regenerative nodular hyperplasia & High & Low? \\
\hline Fulminating hepatic insufficiency & High & Low \\
\hline Budd-Chiari syndrome (late) & High & High \\
\hline Budd-Chiari syndrome (early) & High & High \\
\hline Constrictive pericarditis & High & High \\
\hline Veno-occlusive disease & High & High \\
\hline Myxedema & High & High \\
\hline Nephrogenic Ascites (dialysis) & High & Variable \\
\hline Ascites mix (cirrhosis + peritoneal malignancy) & Low & High \\
\hline Pancreatic Ascites & Low & High \\
\hline Serositis (connective tissue disease) Low High & Low & High \\
\hline Chlamydial / gonococcal ascites & Low & High? \\
\hline Biliary Ascites & Low? & High \\
\hline Ovarian hyperstimulation syndrome & Low & Low \\
\hline Nephrotic syndrome & &
\end{tabular}


Figure 1. Guideline of ascitic fluid managemet.

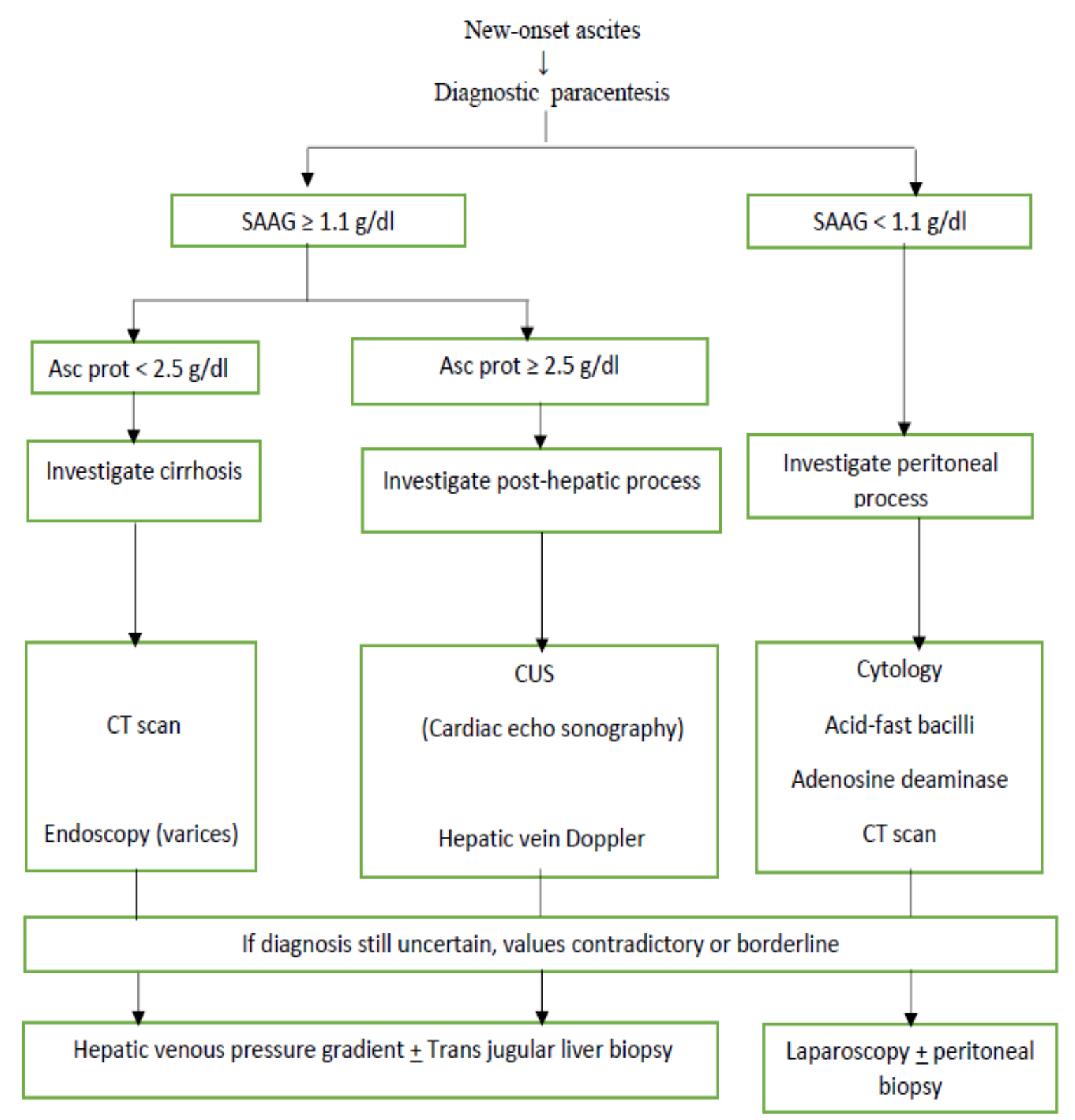

sinusoidal hypertension (hydrostatic pressure) is the cause of ascites, the colloid osmotic gradient (exerted mainly by serum and ascites albumin) must be increased to balance the high hydrostatic pressure that is driving the fluid into the peritoneal cavity. SAAG correlates very well with the hepatic venous pressure gradient $(\mathrm{r}=0.72)$, a measurement of hepatic sinusoidal pressure [7].

The limit value that best distinguishes patients in whom ascites is due to sinusoidal hypertension versus ascites due to peritoneal malignancy is a SAAG of $1.1 \mathrm{~g} / \mathrm{dL}$. A $\mathrm{SAAG}>1.1 \mathrm{~g} / \mathrm{dL}$ indicates that ascites is due to sinusoidal hypertension (e.g., cirrhosis, heart failure) [9].

Interestingly, the SAAG value of $1.1 \mathrm{~g} / \mathrm{dL}$ corresponds approximately to a hepatic venous pressure gradient (HVPG, a mass of sinusoidal pressure) of 11-12 mmHg [7], which is the threshold pressure identified in patients with cirrhotic ascites (see below).

The accuracy of SAAG decreases if samples are not taken simultaneously, if serum albumin levels are too low, or if is Chylous ascites (falsely SAAG is high).

Serum hyperglobulinemia $(5 \mathrm{~g} / \mathrm{dL}$ ) leads to a high concentration of ascitic fluid globulin and may narrow the albumin gradient contributing to oncotic forces. To correct SAAG in the field of a high serum globulin level, uncorrected SAAG must be multiplied by $(0.16) \times$ (serial globulin [in g/dL] + 2.5) [10]. 


\section{Materials and methods:}

This is a prospective study "Case series". Our study included patients hospitalized in the Gastro-Hepatology service University Hospital Center "Mother Teresa" in Tirana, Albania, with ascites.

Patients were followed prospectively from the moment of hospitalization until discharge from the hospital. The study was conducted during the period 2017-2021 with a time span of approximately 4 years.

The study included 72 adult patients, over the age of 18, of both sexes, all of Albanian nationality, with different birthplaces and settlements in different districts of Albania, including the capital with the vast majority of cases.

For the data collection, an epidemiological file was compiled for each patient which was structured with the data obtained from the anamnesis, clinical signs, biological examinations of serum and ascitic fluid, laparoscopy, abdominal echo, CT scanner / MRI, biopsy, final diagnosis.

Part of the ascitic fluid examination was previously assisted by obtaining a diagnostic paracentesis according to the standard technical procedure and in some cases also under ultrasound assistance.

Laboratory-specific, sterile, and disposable glass tubes were used to transport the liquid to the laboratory. Upon completion of the data acquisition, the epidemiological data sheets for each patient were transferred to the Excel program, after which they were transferred to the SPSS (Statistical Package for Social Sciences) Version 16 Chicago Illinois statistical program.
For continuous data (numerical variables) arithmetic means and standard deviations were calculated. The "T-student" test was used to look at the mean differences for the continuous variables. All those changes for which at least $\mathrm{p}<0.05$ were considered important.

The aim of this study was to evaluate the role of SAAG (Serum Ascites Albumin Gradient) in the differential diagnosis between cirrhotic and malignant ascites. The SAAG is obtained by subtracting the value of serum albumin, the value of ascites albumin (from samples to be taken on the same day) and is a reflection of hepatic sinusoidal pressure.

We evaluated prospectively all diagnostic paracentesis in 72 patients with ascites, hospitalized in the GastroHepatology Service at the UHC "Mother Teresa", over a period of 4 years 2017-2021.

The value of SAAG was calculated for each patient between their two groups: 64 patients with cirrhotic ascites and 8 patients with malignant ascites

\section{Results}

All ascitic fluids were analyzed on the laboratory parameters of ascitic albumin values, and at the same time serological albumin through the blood taken for analysis on the same day as the diagnostic paracentesis. The value of SAAG was calculated for each patient between their two groups: 64 patients with cirrhotic ascites and 8 patients with malignant ascites. Higher SAAG values were found in the group of

Table 2. Distribution of ascitic fluid in according the SAAG

\begin{tabular}{|lccc|}
\hline & Cirrhotic Ascites $(\mathbf{N r}=64)$ & Carcinomatous ascites $(\mathbf{N r}=\mathbf{8})$ & P value \\
SAAG & $2.02 \pm 0.42$ & $0.68 \pm 0.19$ & $\mathbf{0 . 0 0 0 1}$ \\
\hline
\end{tabular}

Table 3. Distribution of ascitic fluid in according the age of patients

\begin{tabular}{|lccc|}
\hline & Cirrhotic Ascites $(\mathbf{N r}=64)$ & Carcinomatous ascites $(\mathbf{N r}=8)$ & P value \\
Age & $57.7 \pm 10.1$ & $66.6 \pm 10.6$ & $\mathbf{0 . 0 2 4}$ \\
\hline
\end{tabular}

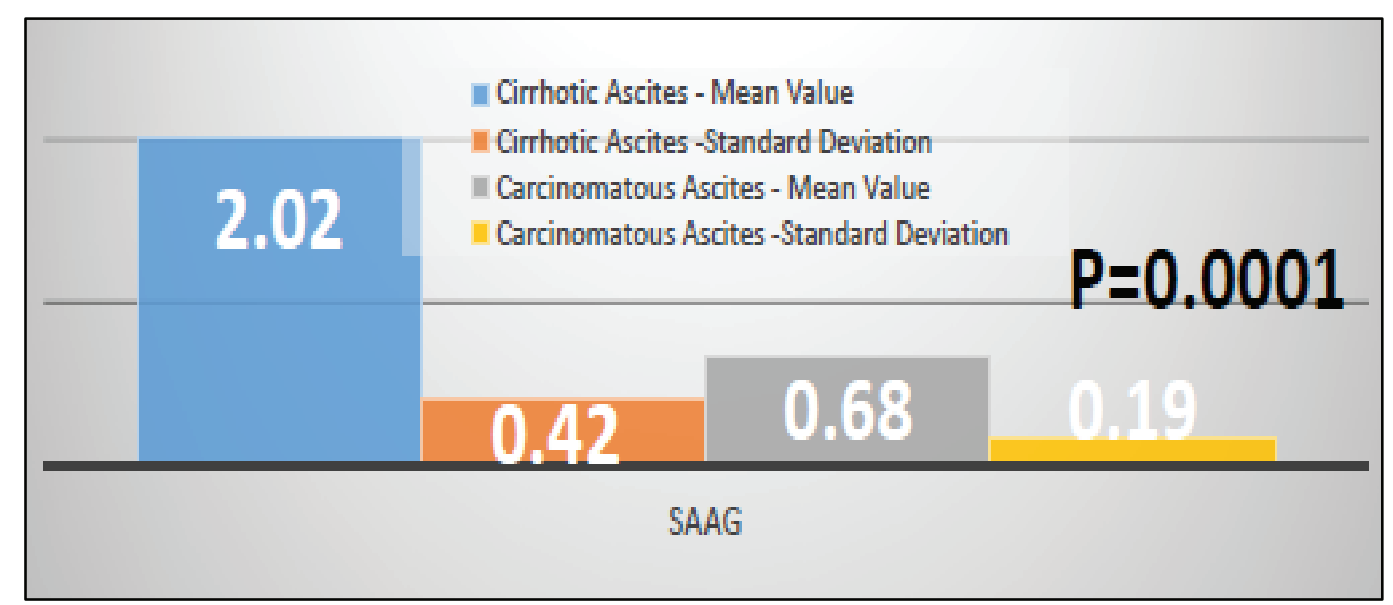

Figure 2. Comparision of SAAG Values 
patients with hepatic cirrhosis $(2.02 \pm 0.42)$ compared to the group of patients with malignant pathology $(0.68 \pm 0.19)$ (Tab. 2).

Also, the mean age of subjects with carcinomatous ascites (peritoneal carcinoma) was higher compared to subjects with cirrhotic ascites (approximately 9 years) with a significant difference between them $(\mathrm{p}<0.024)$ (Tab. 3)

This prospective study showed statistically significant differences ( $p<0.0001$ ) between cirrhotic ascites and malignant ascites in terms of SAAG, emphasizing the important role of diagnostic paracentesis and in particular the SAAG in the differential diagnosis of ascitic fluid, in accordance with cut-off values $\geq 1.1 \mathrm{~g} / \mathrm{dl}$ referring to ascites from portal hypertension, which suggests a nonperitoneal cause of ascites. (Fig. 2)

\section{Discussion}

In our study it was observed that the mean age of subjects with carcinomatous ascites (peritoneal carcinoma) was higher $(66.6 \pm 10.6)$ compared to subjects with cirrhotic ascites $(57.7 \pm 10.1)$ with a significant difference between them $(\mathrm{p}<0.024)$.

Dubey et al. have also shown in another prospective study conducted from December 2014 to December 2015, in which 100 subjects with ascitic fluid were studied, an age difference of about 14 years was found between 71 patients with cirrhotic ascites and 12 patients with malignant ascites, where the mean age values for the respective categories were $40.62 \pm 10.98$ for cirrhotic ascites and 64.17. 10.3 for malignant ones [11].

The one that had the greatest importance in terms of the number of studies in which the significance between cirrhotic and malignant ascites was described, is the SAAG gradient which in our study was presented with a statistically significant difference between the mean values between the respective categories $(2.02 \pm 0.42$ in cirrhotic ascites and $0.68 \pm 0.19$ in malignant ones) with a value of $\mathrm{p}<0.0001$. Dubey et al. in their study supported this significance were numerous starting from the above study, 2014-2015, where the difference in SAAG was significantly higher in the cirrhotic group $(1.62 \pm 0.39)$ compared to the group of malignant ascites $(0.78 \pm 0.43)$ with a value of $p=$ 0.018 [11], and up to other studies such as that of 2016 with 191 subjects with ascitic fluid where it was concluded that SAAG is a good indicator of portal hypertension associated with processes cirrhotic [12].

In other studies Rector et al [13], and Prieto et al. [14] reported that the SAAG was adopted as a newer and more physiological approach to classifying ascites based on the presence or absence of portal hypertension.

Ekpe et al. [15] in their study, published in 2015 in the British Journal of Medicine and Medical Research, significant differences $(\mathrm{P}<0.05)$ were found between the mean values of SAAG in the malignant ascites group $(0.674 \pm 0.484)$, compared to ascites non-malignant $(1,356$ $\pm 0.750)$.
Hoefs et al. [16] set a "cutt off" value of $1.1 \mathrm{gr} / \mathrm{dL}$, which was supported by various other studies $[13,14]$. $\mathrm{SAAG}>1.1 \mathrm{gr} / \mathrm{dL}$ can differentiate cirrhotic ascites from non-cirrhotic ones.

Similar results were observed in our study, with a "cut off" value of $\geq 1.1 \mathrm{gr} / \mathrm{dL}$. SAAG differentiates cirrhotic ascites from non-cirrhotic ones. If SAAG is $\geq 1.1 \mathrm{gr} / \mathrm{dL}$, the patient is considered to have portal hypertension. In contrast, if SAAG is $<1.1 \mathrm{gr} / \mathrm{dL}$, the patient is unlikely to have portal hypertension but other pathologies such as malignant pathologies or tuberculosis.

SAAG is currently included in the Diagnostic Guidelines and is recommended for the management of ascites in cirrhosis by the American Society for the Study of Liver Disease (AASLD) and the British Association of Gastroenterology [11].

The European Association for the Study of Liver (EASL) also mentions in its Guidelines that ascites from portal hypertension can be easily differentiated from ascites for other reasons through the SAAG gradient. If SAAG is greater than or equal to $1.1 \mathrm{~g} / \mathrm{dl}$ (or $11 \mathrm{~g} / \mathrm{L}$ ), ascites is attributed to portal hypertension. [17].

\section{Conclusion}

We can confirm that biochemical and cellular examination of ascitic fluid constitutes the first diagnostic operation in patients with accumulation of ascitic fluid in the peritoneal cavity.

SAAG is a very important indicator in the differential diagnosis between cirrhotic ascites and malignant ascites from peritoneal carcinomatosis $(\mathrm{p}<0.0001)$. SAAG $\geq 1.1 \mathrm{gr}$ / dL, portal hypertension. SAAG $<1.1$ gr / dL, malignant pathologies.

\section{Author Contributions}

HD. conceived and designed the analysis, collected the data, treatment of all the patients in the article, observed the patients, contributed the data and analyses tools, performed the analysis and Interpretations, literature search, wrote the paper, other contributions (take the pictures), supervisor of the project, critical reviewer. RB comprehended and designed the analysis, treatment of all the patients in the article, contributed the data and analyses tools, performed the analysis, wrote the paper, critical reviewer. ER, JB conceived and designed the analysis, collected the data, treatment of all the patients in the article, wrote the paper, other contributions critical reviewer, literature search. RB considered and designed the analysis, collected the data, treatment of all the patients in the article, wrote the paper, other contributions (take the pictures), critical reviewer, literature search

\section{Declaration of any potential financial and non-financial conflicts of interest:}

The authors declare that they have no known competing financial interests or personal relationships that could have appeared to influence the work reported in this paper. 
Ethics approval and consent to participate - all the patients/ their parents have signed informed consent.

Consent for publication - all the patients/their parents have signed informed consent

Clinical trial registration information provided - not applicable

We confirm $t$ hat $t$ he manuscript, i ncluding $r$ elated data, figures and $t$ ables $h$ as $n$ ot been p reviously $p$ ublished and that the manuscript is not under consideration elsewhere.

\section{References}

1. Fede G, D'Amico G, Arvaniti V, et al. Renal failure and cirrhosis: a systematic review of mortality and prognosis. $\mathrm{J}$ Hepatol. 2012 Apr. 56(4):810-8.

2. History: Liver \& Ascites, University of Washington, Department of Medicine, Advanced Physical Diagnosis Learning and Teaching at the Bedside, Edition 1

3. Mark Feldman, Lawrence Friedman, Lawrence Brandt: Sleisenger and Ford tran's Gastrointestinal and Liver Disease Ninth Edition, 3rd May 2010.

4. The Merck Manual of Diagnosis and Therapy, 17th Edition 1999 (Centennial Edition) 17th Edition by Mark H. Beers (Editor), Robert Berkow (Editor)]

5. Yamada's Textbook of Gastroenterology, Sixth Edition. Edited by Daniel K. Podolsky, Michael Camilleri. J. Gregory Fitz, Anthony N. Kalloo, Fergus Shanahan, and E Timothy C. Wang. (C) 2016 John Wiley \& Sons, Ltd. Published 2016 by John Wiley \& Sons, Ltd.2087-2090\}

6. Younas M, Sattar A, Hashim R, Ijaz A, Dilawar M, Manzoor SM, Ali A, Khan FA. Role of serum-ascites albumin gradient in differential diagnosis of ascites. J Ayub Med Coll Abbottabad. 2012 Jul-Dec; 24(3-4): 97-9. PMID: 24669623.

7. Hoefs JC. Serum protein concentration and portal pressure determine the ascitic fluid protein concentration in patients with chronic liver disease. J Lab Clin Med 1983; 102:260.

8. Henriksen JH. Colloid osmotic pressure in decompensated cirrhosis. A 'mirror image' of portal venous hypertension. Scand J Gastroenterol 1985; 20:170.
9. Pare P, Talbot J, Hoefs JC. Serum $\square$ ascites albumin concentration gradient: a physiologic approach to the differential diagnosis of ascites. Gastroenterology 1983; $85: 240$.

10. Hoefs JC. Globulin correction of the albumin gradient: correlation with measured serum to ascites colloid osmotic pressure gradients. Hepatology 1992; 16:396.

11. T. N. Dubey, Shyam Dawane, Diagnostic Value of Serum Ascites Lipid Gradients in Patients with Ascites, International Journal of Contemporary Medical Research, September 2016, ISSN (Online): 2393-915X; (Print): 2454-7379 | ICV: 50.43 Volume 3 | Issue 9 | pg:2572-2577

12. Angeleri A, Rocher A, Caracciolo B, Pandolfo M, Palaoro L, Perazzi B. New Biochemical Parameters in the Differential Diagnosis of Ascitic Fluids. Gastroenterology Res. 2016 Feb; 9(1):17-21. doi: 10.14740/gr700w. Epub 2016 Mar 8. PMID: 27785319 ; PMCID: PMC5051108.

13. Rector WG Jr, Reynolds TB. Superiority of the serum ascites albumin difference over the ascites total protein concentration in separation of "transudative" and "exudative" ascites. Am J Med. 1984; 77:83-85

14. Prieto M, Gómez-Lechón MJ, Hoyos M, et al. Diagnosis of malignant ascites. Comparison of ascitic fibronectin, cholesterol, and serum-ascites albumin difference. Dig Dis Sci. 1988; 33:833-838.

15. E. E. L. Ekpe, A. J. Omotoso. The Relevance of Ascitic Lactate Dehydrogenase (LDH) and Serum Ascites Albumin Gradient (SAAG) in the Differential Diagnosis of Ascites among Patients in a Nigerian Hospital, British Journal of Medicine \& Medical Research 8(3): 211-219, 2015, Article no. BJMMR.2015.441 ISSN: 2231-0614, pg. 211-219

16. Hoefs JC. Increase in ascites white blood cell and protein concentrations during diuresis in patients with chronic liver disease. Hepatology. 1981; 1: 249-254.R

17. Ginès Pere, Angeli Paolo, Lenz Kurt, Møller Søren, Moore Kevin, Moreau Richard, Merkel Carlo, Larsen Helmer, Bernardi Mauro, Garcia-Tsao Guadalupe, Clinical practice guidelines on the management of ascites, spontaneous bacterial peritonitis, and hepatorenal syndrome in cirrhosis, EASL: European Association for the Study of the Liver, Journal of Hepatology 2010 vol. 53j 397-417 